\title{
Frequency Stability Enhancement for Low Inertia Systems using Synthetic Inertia of
} Wind Power

Nguyen, Ha Thi; Yang, Guangya; Nielsen, Arne Hejde; Jensen, Peter Højgaard

Published in:

Proceedings of 2017 IEEE PES General Meeting

Link to article, DOI:

10.1109/PESGM.2017.8274566

Publication date:

2017

Document Version

Peer reviewed version

Link back to DTU Orbit

Citation (APA):

Nguyen, H. T., Yang, G., Nielsen, A. H., \& Jensen, P. H. (2017). Frequency Stability Enhancement for Low Inertia Systems using Synthetic Inertia of Wind Power. In Proceedings of 2017 IEEE PES General Meeting IEEE. https://doi.org/10.1109/PESGM.2017.8274566

\section{General rights}

Copyright and moral rights for the publications made accessible in the public portal are retained by the authors and/or other copyright owners and it is a condition of accessing publications that users recognise and abide by the legal requirements associated with these rights.

- Users may download and print one copy of any publication from the public portal for the purpose of private study or research.

- You may not further distribute the material or use it for any profit-making activity or commercial gain

- You may freely distribute the URL identifying the publication in the public portal 


\section{Frequency Stability Enhancement for Low Inertia Systems using Synthetic Inertia of Wind Power}

\author{
Ha Thi Nguyen, Guangya Yang, and Arne Hejde Nielsen \\ Department of Electrical Engineering \\ Technical University of Denmark \\ Kgs. Lyngby, 2800 Denmark \\ (thangu, gyy, ahn)@elektro.dtu.dk
}

\author{
Peter Højgaard Jensen \\ Energy Automation \\ Siemens A/S \\ 2750 Ballerup, 2800 Denmark \\ peter_hoejgaard.jensen@siemens.com
}

\begin{abstract}
High-level integration of renewable energy sources in power system leads to the displacement of conventional generators and consequently challenges in power system frequency stability are introduced. To mitigate the negative impact of significant wind power penetration in the grid on the frequency stability, this paper proposes supplementary control methods to implement synthetic inertia for doubly-fed induction generator (DFIG) based wind energy system during frequency excursions. Different control strategies and activation schemes are analyzed and implemented on the Western Danish renewable-based system using-real time digital simulator (RTDS) to propose the best one for the synthetic inertia controller. From the comparative simulation results, it can be concluded that the method using a combination of both the frequency deviation and derivative as input signals, and the under-frequency trigger provides the best dynamic response in term of the system frequency stability improvement.
\end{abstract}

Index Terms-Doubly-fed induction generator, frequency stability, low inertia systems, synthetic inertia, wind power.

\section{INTRODUCTION}

With the progressive replacement of the traditional generators by non-synchronized renewable-based power plants the grid level of synchronous power reserves and inertia constant in the system becomes reduced significantly. The unique characteristics of renewable energy sources responses have issued many challenges to the reliability and stability of modern power systems [1]. One of the biggest concerns regarding the large-scale wind farm penetration in the power system is its impact on power system frequency stability due to the lack of positive frequency response to frequency excursions, i.e., large load fluctuations or generator trips. Therefore, the dynamic frequency support capability of wind power plants (WPPs) are required to guarantee that the frequency stability is not compromised. In addition, the contributed inertia from wind generators can improve the grid's adopt capacity for a wind farm, and further promote its sustainable development.

In order to maintain system frequency stability in a grid with a high penetration level of wind power into the grid, WPPs have to take on more and more tasks of conventional power

This work is supported by Synchronous Condenser Application (SCAPP) project funded by ForskEL program, grant no. 12196 administrated by Energinet.dk (www.scapp.dk) plants regarding frequency control. At the moment, ENTSO$\mathrm{E}$ has the network code that applies to all grid-connected generators, i.e, in continental Europe WPPs with rated power above $50 \mathrm{MW}$, in the UK above $10 \mathrm{MW}$, and in Ireland above 5 MW. These WPPs must be equipped with a power control system for frequency response [2].

It is known that the WPPs are currently adopting the typical vector control method based on the phase-locked-loop (PLL) synchronizing technique. Because of the stable and precise dynamic response of PLL, the positive sequence component phase is obtained rapidly and accurately, even if the system frequency is distorted. This makes WPPs decoupled to the system frequency response and thus an interesting control method is proposed to WPPs supply inertia support like conventional generating units do is extremely necessary.

The inertia constant of traditional generators are in the range of 2-9 s [3] depending on the type of generator, and this inertia is automatically available when the system frequency tends to decrease or increase following a disturbance or losses of generation or demand. The wind turbine inertia constants are typical between 4 and $6 \mathrm{~s}$, however, they do not participate naturally in frequency control because they mostly interface with the grid by power electronic converters [1].

In the case of doubly-fed induction generator (DFIG), the back-to-back converter is located at the rotor circuit side, the power electronic converter must only be sized with nearly one third (1/3) the power of the generator. Thus, the cost of systems using DFIG is always lower than the cost of systems with full converter generator like permanent magnet synchronous generator. Although the stator windings of DFIG connect directly with the grid, the electrical power generated by the unit is effectively tightly controlled by the current control loops of the converter. As a result, following an electrical disturbance, the converter quickly control the output to its predisturbance value, thereby effectively decoupling the potential inertial response of DFIG from the grid.

At the moment, there have already been many papers proposing several inertial strategies to make wind farms participate in the system frequency regulation [4]-[9]. In [4], a coordinated frequency control of pitch angle and rotor speed control for a DFIG based wind turbine is proposed for low, medium and high wind speed modes. However, only 
$\frac{d f}{d t}$ control loop is assessed in this paper. The active power control of a DFIG is investigated in [5] in a way to meet the operators request and maintain frequency stability, without losing the stability of operation during different wind speeds. A droop control strategy as an alternative for the synthetic inertia strategy to supply inertial response is presented in [6]. However, the paper just focuses on the droop control without inertia constant gain. A comparison of different inertia control methods for WPP is studied in [7] without mentioning about the detailed control methods. A frequency controlling wind power modeling of different control strategies is investigated in [8], but it is studied on full power converter wind power plants and focused on the primary frequency control. In [9], several operating strategies for DFIGs to support the system frequency are proposed, however, they just use the speed deviation of wind generators as the input signal to control the active power command.

The literature about the synthetic synchronization listed above is focused on the control strategies without studying activation schemes. In [10], the author studies about the coordinated frequency control of wind turbines in power systems with high wind power penetration, a coordination of inertial response and grid event detector with a simultaneous meet of three conditions is investigated. However, it takes a long time for calculating the demanded inertial response and $\frac{d f}{d t}$. It may result in an activation delay for the controller. This paper will analyze and implement the synthetic inertia control methods combine with the activation scheme for DFIG based WPP which is cheaper because of partial scale converter generator, and capable of delivering more power at lower wind speeds, using the Western Danish system as the background. A comparison of control methods and activation schemes are analyzed and implemented for SI controller of DFIG on the testing system. From the comparative simulation results, the best one will be proposed to improve the system frequency stability during the frequency excursion.

The rest part of the paper is organized as follows. In Section II, the principle and the control design for different synthetic inertia strategies and activation schemes for DFIG are explained. The analysis with different synthetic inertia implementations is compared in the time-domain simulation section. Conclusions that can be drawn from the analysis are presented in section VI.

\section{SYNTHETIC INERTIA CONTROLLERS AND ACTIVATION SCHEMES FOR DFIG}

In a power system in the steady state, the total generation $P_{g e n}$ always equals the sum of the total demand and line losses $P_{\text {load }}$ to keep the frequency stable in the acceptable range $(0.001-0.1 \mathrm{~Hz})$ [11]. In the case of a sudden change of production or load, the kinetic energy which is stored in the rotating parts of the generators and motors remained online on the system, will react to against the power imbalance. The system frequency is achieved a robust stability if the active power is maintained balance which is determined by (1).

$$
\Delta P=\frac{d E_{k i n}}{d t}=J \omega \frac{d \omega}{d t}=P_{\text {gen }}-P_{\text {load }}=0
$$

where $E_{k i n}$ is the kinetic energy of rotating machines connected to the system, $J$ is the total system inertia, and $\omega$ is angular velocity of the rotating machine.

During a sudden load increase, the output power of generators cannot immediately go up, the initial frequency variation of the system will depend on the kinetic energy release from rotating machines $J$. This is so-called "inertial response" and has an important impact on the system frequency stability. Few second after the disturbance, the primary power reserves will be supplied to limit the frequency deviation.

When WPPs replace the conventional generators, the total system inertia decrease because wind generators almost connect to the grid through the converters. However, the kinetic energy contains in the rotor of wind generators is nearly as much as the directly-coupled synchronous generators. It is necessary to implement an appropriate control method in the converter to use the kinetic energy for supporting inertial response during frequency excursions.

\section{A. Control Design}

Synthetic inertia (SI) controller of WPP imitates the inertial response behavior of the synchronous generators, which releases or absorbs the kinetic energy for the system during power imbalances. Fig. 1 shows the overall control structure of DFIG combined to synthetic inertia controller. In the steady state, the active power set point is governed by the maximum power point tracking algorithm (MPPT) that does not react to the changes in the system frequency, and it is given by $P_{0}$ in Fig. 1a).

When a frequency disturbance occurs, there is an inertial response signal $P_{\text {extra }}$ added to the active power reference. This additional signal comes from two control loops: the frequency derivative $\frac{d f}{d t}$ loop and the frequency deviation $\Delta f$ loop as Fig. 1b).

To get the input signals of these supplementary control loops, the system frequency is measured and filtered by a lowpass filter to avoid the noise in the frequency measurement. The first loop is in charge of additionally providing an offset power signal $P_{1}$ that is proportional to frequency gradient $\frac{d f}{d t}$ an is expressed by (2).

$$
P_{1}=-K_{i n} \frac{d f}{d t}
$$

The second loop is in charge of supplying an additional power signal, which is proportional to the frequency deviation from its nominal value, so its output $P_{2}$ lasts until the rated frequency level is recovered and is calculated by (3).

$$
P_{2}=K_{\text {droop }} \Delta f
$$

A dead band $( \pm 0.015 \mathrm{~Hz})$ is used to prevent the differentiation of a noisy input signal that may lead to large variations in the value of outputs. This may result in heavy power pulsations 

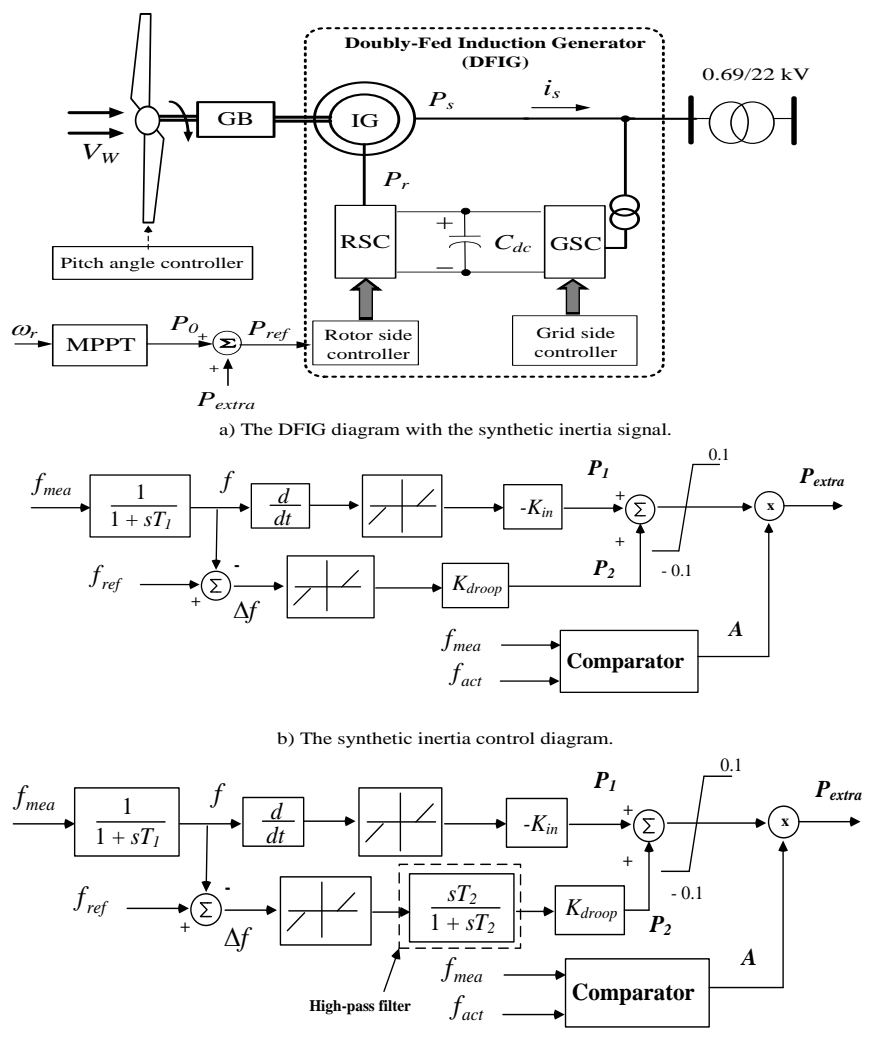

c) The synthetic inertia control diagram with high-pass filter.

Fig. 1. The overall control structure of the synthetic inertia and DFIG.

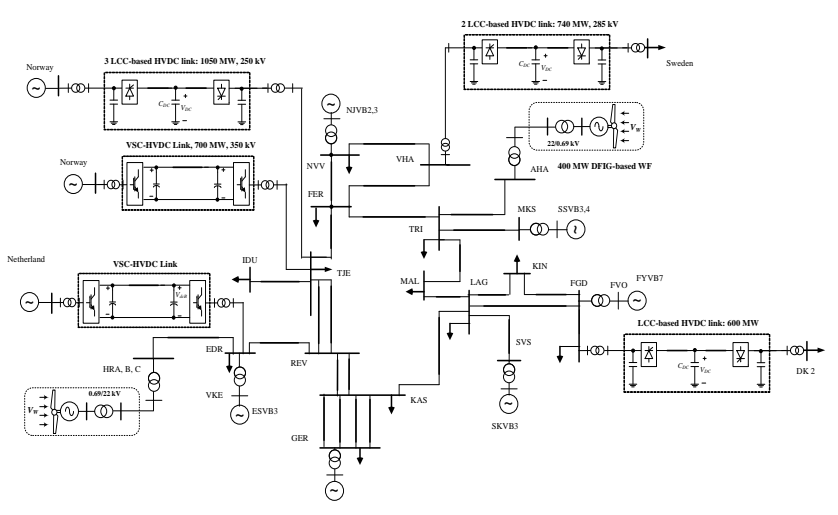

Fig. 2. Single-line diagram of Western Danish power system.

in the drive-train of the wind turbine in the normal operating condition.

Therefore, the complete active power reference of the rotor side converter is given by (4)

$$
P_{\text {ref }}=P_{0}-K_{\text {in }} \frac{d f}{d t}+K_{\text {droop }} \Delta f
$$

Two loops have different effects at enhancing the system frequency stability. The $\frac{d f}{d t}$ loop works when a rate of change of frequency (ROCOF) is very high. On the other hand, the $\Delta f$ loop plays an important role in inertia control when the system frequency goes up or down greatly. As a result, they make the system frequency waveform more and more smoothly than no or only one control loop inertia support for DFIG.

However, in this case during the frequency drop, DFIG is forced to operate away from the maximum power point tracking with the rotor speed reduction. This makes DFIG do not recover to the pre-disturbance operating point, and if the wind generator works with low speed, the further lower rotor speed during disturbance can make wind generator stop working. To handle this problem, a high-pass filter which avoids a contribution of the droop controller in steady state is added as Fig. 1c). This filter makes $P_{2}$ equal to zero when system frequency obtains the new equilibrium point after the disturbance, and DFIG recovers to the pre-disturbance operating point. It can be seen clearly in the simulation results in next section. It is important to tune properly these two gain during the SI implementation. If the two gains are selected so high or so low, it may cause a poor controller for the wind power. For instance, in the low wind speed condition, the contribution of kinetic energy from WPPs should be low, so these two gains should be chosen with low values. On the other hand, with the high wind speed condition, these two gains cannot be selected too high, because it may result in the over-current limit for the converter and high mechanical stress for the wind turbine.

One more important thing is that the extra active power signal from SI is limited to \pm 0.1 p.u. to avoid the current limit of the IGBTs in the converter. It means that when DFIG works at its rated power operating condition, the total current is less than or equal to 1.1 p.u. during frequency disturbances.

\section{B. Activation schemes}

With the SI implementation for WPPs is a necessary requirement for the low inertia systems which use a majority of renewable energy sources. However, control schemes used to active the SI plays an important role and need to be concerned thoroughly in this controller. The proper combination of SI controller and activation schemes makes the better emulated inertial response for wind turbines.

Two trigger schemes are presented in this section that are called "over/under-frequency trigger" and "maximumfrequency gradient trigger" [12]. The first one compares the system frequency measurement with the frequency action that should active synthetic inertia of WPPs participate in the system frequency regulation. If the frequency measurement $f_{m e a}$ is less or greater than the minimum $f_{\text {act min }}$ or maximum $f_{\text {act max }}$ action values, a trigger signal $A$ is generated to active the SI controller of WPPs as Fig. 1. The trigger function of this scheme can be expressed as follows:

$$
\left\{\begin{array}{l}
\text { if } f_{\text {mea }} \leq f_{\text {act } \min } \text { or } f_{\text {mea }} \geq f_{\text {act } \max }: \operatorname{set} A=1 \\
\text { else }: \operatorname{set} A=0
\end{array}\right.
$$

The second one measures the system frequency and then calculates $\frac{d f}{d t}$, when the rate of change of frequency exceeds to the setting value $\left|\frac{d f}{d t}\right|_{a c t}$, an activation signal $A$ is created. This scheme can be defined as follows: 

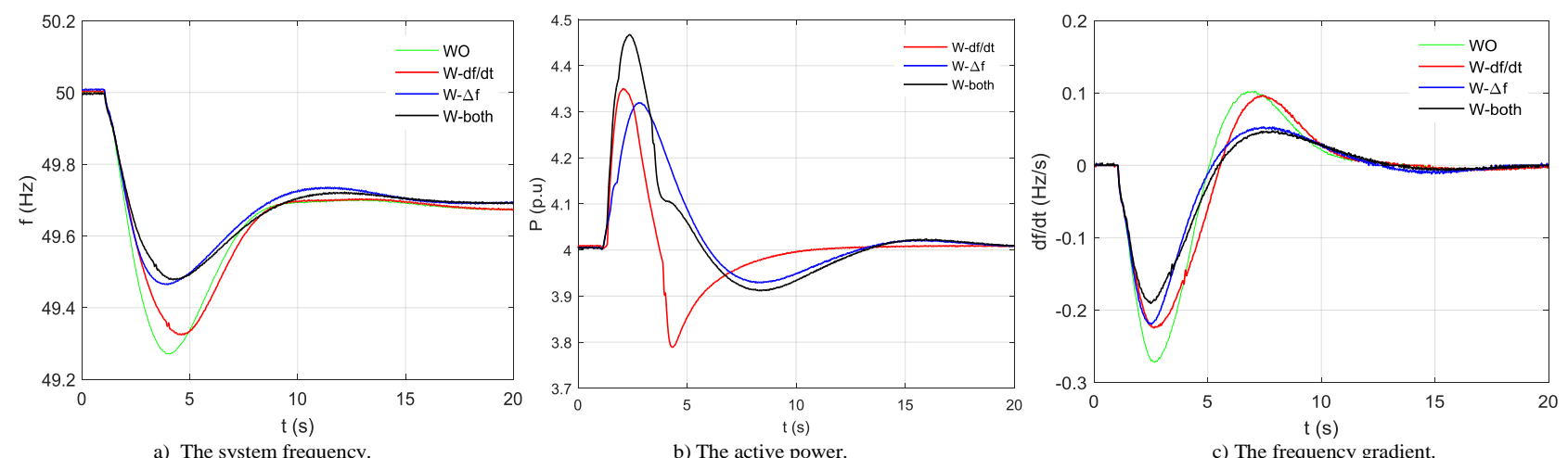

Fig. 3. The dynamic responses of the system frequency, the DFIG active power and the frequency gradient during a $200 \mathrm{MW}$ load increase.

$$
\left\{\begin{array}{l}
\text { if }\left|\frac{d f_{\text {mea }}}{d t}\right| \geq\left|\frac{d f}{d t}\right|_{\text {act }}: \operatorname{set} A=1 \\
\text { else }: \operatorname{set} A=0
\end{array}\right.
$$

The second scheme is similar to the typical logic control in ROCOF relays. However, it is hard to get the accurate value of $\frac{d f}{d t}$ and takes a time to calculate after the frequency measurement. Consequently, it may result in a response delay or a malfunction for the controller. In addition, an outstanding system frequency response is demonstrated in [12] when using the under-frequency trigger for the SI controller. Therefore, this paper will use the first activation scheme to active the SI controller.

\section{Time-Domain Simulation}

In this section, the SI controller for DFIG is applied to the Western Danish renewable-based system which uses the majority of converter interfaced generation like wind power and importing HVDC connections as the testing system as shown in Fig. 2. The system configuration, the equivalent system inertia and how the system frequency responses with different wind power penetrations during a disturbance are documented more detail in [13]. The SI controller is implemented on an aggregated model of a $400 \mathrm{MW}$ DFIG based wind farm located at Alholt as shown in Fig. 2. The dynamic model of DFIG using real-time digital simulator (RTDS) during underfrequency incidents is investigated to achieve the objective of the SI controller.

Two different wind conditions studies are discussed to demonstrate the performance of SI controller during a load increase. These two different wind speeds with $12 \mathrm{~m} / \mathrm{s}$ and 11 $\mathrm{m} / \mathrm{s}$ are simulated in this section to guarantee that the pitch angle controller is not activated. The system frequency, the frequency gradient and the dynamic responses of DFIG are compared for the testing system in different control strategies.

Fig. 3 shows the dynamic responses of the system frequency and DFIG active power at the rated wind speed $(12 \mathrm{~m} / \mathrm{s})$ during a $200 \mathrm{MW}$ load increase in Germany at $\mathrm{t}=1.25 \mathrm{~s}$. The green lines and black lines represent the responses of the power system without SI controller and with both two control loops, whereas the red lines and blue lines symbolize the values of the system with the first control loop $\left(\frac{d f}{d t}\right)$ and with the second control loop $(\Delta f)$, respectively. It can be seen from Fig. 3a) that the system frequency is improved when the SI controllers implement. With the first control loop (red line), the frequency decreases more slowly, but the frequency nadir is slightly lifted. The much larger enhancement in the frequency nadir is obtained by the second control loop and both two control loops, which increases from approximately $49.26 \mathrm{~Hz}$ to around $49.5 \mathrm{~Hz}$. In addition, considering the active power responses of three SI strategies, it can be observed that the $\frac{d f}{d t}$ loop can release with higher active power in short time for the power system during the frequency drop. However, this may result in higher mechanical stress for the wind turbine. This issue is dealt with the coordination of two control loops as shown in Fig. 3b). As expected, with both two control loops, the frequency gradient is significantly decreased only $0.18 \mathrm{~Hz} / \mathrm{s}$ instead of $0.275 \mathrm{~Hz} / \mathrm{s}$ without SI controller as shown in Fig. 3c).

However, the supplementary signal of the second loop still lasts until the system frequency reaches its nominal value. To address this issue, the high-pass filter is added to the control loop to prevent the participation of $P_{2}$ on the primary frequency control. It can be observed in the second case study that investigates the SI implementation on the same testing system to compared the SI controller with and without highpass filter during a sudden $100 \mathrm{MW}$ load increase. With the lower wind speed $(11 \mathrm{~m} / \mathrm{s})$, the power output of DFIG does not reach its rated power (400 $\mathrm{MW})$.

As can be seen clearly in Fig. 4, the SI strategy with the high-pass filter (HPF) results in a higher frequency nadir and a lower the frequency gradient. The extra active power output of DFIG is higher compared to without HPF, it means more kinetic energy is extracted from the rotor, while the rotational speed deviation is almost the same. Without HPF, the output signal $P_{2}$ of the second loop still exists until the system frequency hits the rated value, it makes the power reference higher compared to the pre-disturbance value. This results in the higher mechanical torque and lower rotor speed when the 

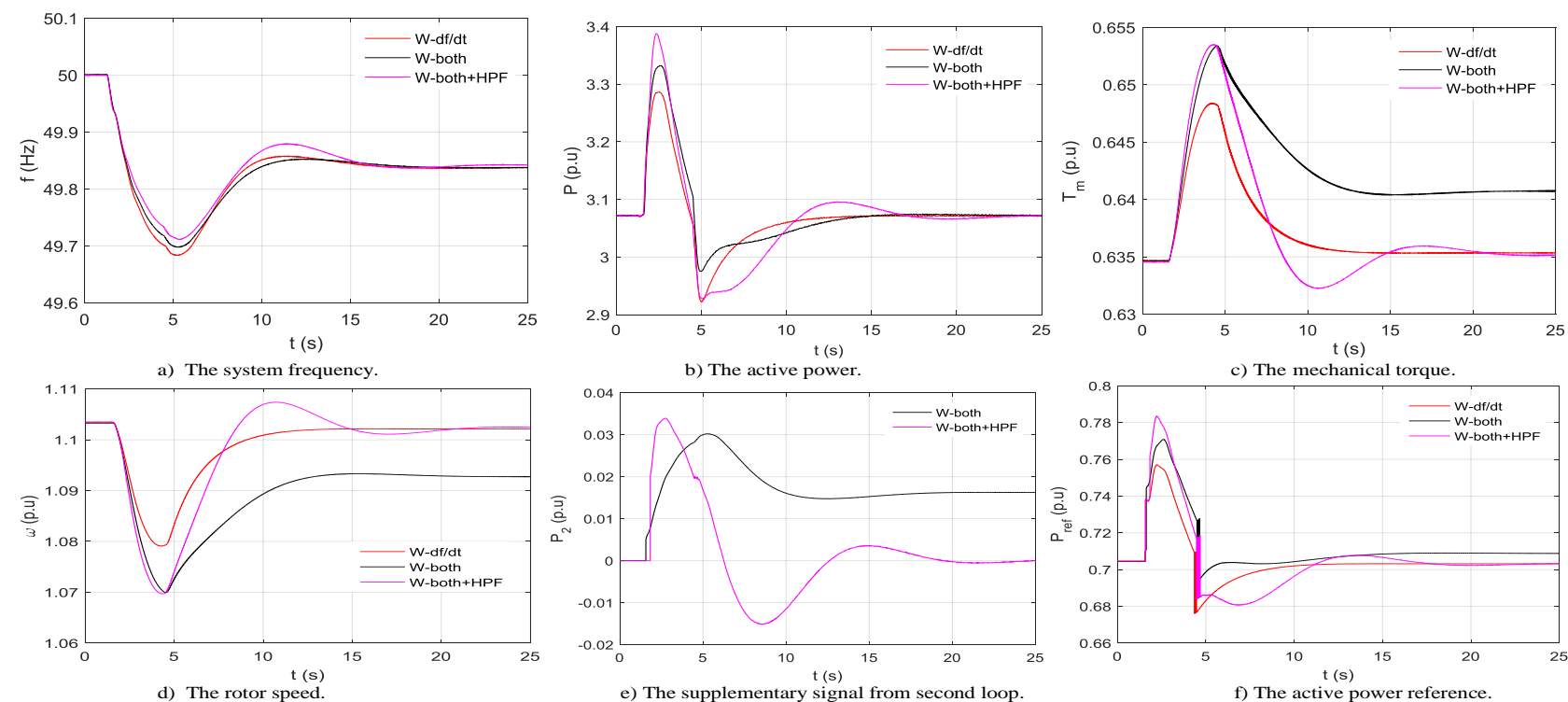

Fig. 4. The dynamic responses of the system frequency and DFIG during a $100 \mathrm{MW}$ load increase

system frequency reaches a new steady state point as shown in Fig. 4 c) to e).

As the expected purpose of HPF, the rotor speed and mechanical torque recover the pre-disturbance values when the system reaches a new steady state point as shown in Fig. 4d).

From the simulation results in Fig. 3 and Fig. 4, it can be concluded that the SI controller with HPF combined to under-frequency trigger performs the best frequency stability improvement during a sudden load change. It should be considered to implement for the low inertia systems that use a majority of renewable power plants.

In the testing case with these wind speeds, $K_{\text {in }}$ and $K_{\text {droop }}$ are selected 30 and 6 , respectively. However, these two gains should be selected according to the wind speed conditions. It means that they should be chosen lower in low wind speed conditions and higher in high wind speed conditions to reach a rich controller for the SI strategy.

\section{CONCLUSION}

With the rapidly increase of wind power penetration on the power system at the moment, the grid code requirements on frequency stability for integration of large wind farms are necessary for the secure and stable operation of the network. Because of the decoupled control between the rotor speed and the system frequency, the inertial response of DFIG-based wind turbines for the frequency support is almost unavailable. However, the SI controller can be implemented by DFIG active power regulation for the frequency support, and the capacity for the SI response depends on the pre-disturbance operating condition of wind turbine that can be controlled through two gains ( $K_{\text {in }}$ and $K_{\text {droop }}$ ) within the steady state operational limits.

The simulation results show that the combination of the proper SI strategy and the activation scheme can extract more kinetic energy from wind generators for the better frequency stability enhancement.

\section{REFERENCES}

[1] J. Ackermann, Wind Power in Power Sysems, vol. 140, no. February, Hoboken, NJ: Wiley, 2005, p. 545.

[2] F. Daz-Gonzlez, M. Hau, A. Sumper, and O. Gomis-Bellmunt, "Participation of wind power plants in system frequency control: Review of grid code requirements and control methods," Renew. Sustain. Energy Rev., vol. 34, pp. 551-564, 2014.

[3] J. J. Grainer and W. Stevenson, Power System Analysis, 1994.

[4] Z.-S. Zhang, Y.-Z. Sun, J. Lin, and G.-J. Li, "Coordinated frequency regulation by doubly fed induction generator-based wind power plants," IET Renew. Power Gener., vol. 6, no. 1, p. 38-47, 2012.

[5] L. R. Chang-Chien and Y. C. Yin, "Strategies for operating wind power in a similar manner of conventional power plant," IEEE Trans. Energy Convers., vol. 24, no. 4, pp. 926-934, Dec. 2009.

[6] J. Van De Vyver, J. D. M. De Kooning, B. Meersman, L. Vandevelde, and T. L. Vandoorn, "Droop control as an alternative inertial response strategy for the synthetic inertia on wind turbines," IEEE Trans. Power Syst., vol. 31, no. 2, pp. 1129-1138, Mar. 2016.

[7] Z. Zhang, Y. Wang, H. Li, and X. Su, "Comparison of inertia control methods for DFIG-based wind turbines," in Proc. 2013 IEEE ECCE Asia Downunder - 5th IEEE Annu. Int. Energy Convers. Congr. Exhib. IEEE ECCE Asia 2013, pp. 960-964.

[8] M. Wang-Hansen, R. Josefsson, and H. Mehmedovic, "Frequency controlling wind power modeling of control strategies," IEEE Trans. Sustain. Energy, vol. 4, no. 4, pp. 954959, 2013.

[9] L. R. Chang-Chien, W. T. Lin, and Y. C. Yin, "Enhancing frequency response control by DFIGs in the high wind penetrated power systems," IEEE Trans. Power Syst., vol. 26, no. 2, pp. 710718, 2011.

[10] G. C. Tarnowski, "Coordinated frequency control of wind turbines in power systems with high wind power penetration," Ph.D. dissertation, Dept. Elec. Eng., Tech. Univ. Denmark, Lyngby, 2011.

[11] P. Kundur, Power System Stability and Control, 1st ed. New York: McGraw Hill, 1994.

[12] F. G. Gonzlez-Longatt, "Activation schemes for synthetic inertia controller on wind turbines based on full rated converter," in Proc. IEEE PowerTech 2015, pp. 1-5.

[13] H. T. Nguyen, G. Y. Yang, A. H. Nielsen, and P. H. Jensen, "Frequency stability improvement of low inertia systems using synchronous condensers," unpublished. Presented at the IEEE International Conference on Smart Grid Communications, Sydney, Australia, 6-9 November 2016. 